\title{
The Moving Competitive Advantage of Enterprises: Situation Advantage
}

\author{
Jinling Li and Renjing Liu \\ School of Management, Xi' an Jiaotong University,7 10049,Xi' an Shaanxi, \\ P.R. China \\ renjingl@163.com
}

\begin{abstract}
In this paper, the situation advantage is defined from the angle of management innovation, which is another one of the competitive advantage of companies in incomplete information. The essential characteristics of the situation advantage are analyzed in detail, and three factors are proposed, such as the excellent boss, competitive information and added value, which bring about the situation advantage.
\end{abstract}

\section{Statement of the Problem}

Many academicians have dealt with the situation advantage from different viewpoints in their studies of the competitive advantage of MNC (Multinational Corporation). For example, Hymer [1] emphasizes the monopoly advantage of MNC, and Casson [2] stresses the advantage of interior. There are also some other academicians who stress the local advantage, as well as the compromise theory which is bases on all these theories. Danning [3] thinks that the MSC must possess three kinds of predominance when they intend to invest abroad: the ownership advantage, the interior advantage and the local advantage. The keystone of Danning's [3] research is not the competition of the MNC for he investigates the problem from the angle of the international production of enterprise. The local advantage, the interior advantage and the ownership advantage he summarizes mainly explain the MNC's motivation for investment and the predominance of local enterprise.

In addition, Baud [4] has put forward such an idea that the competition stratagem made by an enterprise needs create three competitive advantages: the cost advantage, the advantage of indiscrimination of product and the advantage which fasten on the market subdivision. With the predominance as above, the enterprise would possess the competitive advantage and could achieve rich and generous returns. In addition, the competition stratagem of an enterprise is related not only to its overseas benefit, but also to the subsistence and development of the enterprise. Vernon [4] probes into the source of the 
advantage and points out that the competitive advantage comes from the innovation of the products and meanwhile, the business chance is one of the advantages.

The scholars mentioned above have discussed how an enterprise acquires the competitive advantage from the point of the inherent predominance an enterprise possesses while others do not have. This sort of predominance could be considered as a composition of the hard wares of the enterprise. Vernon's last viewpoint [4] is that it is vital for an enterprise to make good use of chance and create the competitive advantage. Chance is one of the qualifications which encourage the enterprise to gain a sort of unexpected competitive advantage that other enterprise can not duplicate. Especially in such an information age, the speedy development of technology render the significant transformation of the organization structure and the prosecution idea, the innovation of management is an important object the enterprises pursue and the enterprises' management must adapt to the demand of the modern corporation's technology and the development of the times,

In the game among the enterprises, the alteration of the game element could affect the result of conflict. So we bring forward another competitive advantage from the angle of management innovation, the situation advantage. An enterprise must have an insight into business chance and recognize, grasp and make use of every opportunity, and especially have a capability for creating a situation advantage, which helps the enterprise develop itself and strengthen the competitive capacity. This competitive advantage can be regarded as a composition of the soft wares of an enterprise, and it is a kind of 'soft advantage' created by the innovative management of an outstanding entrepreneur, a kind of wisdomwitted competitive advantage, and the sapient fruit of the entrepreneur.

\section{The Concept of Situation Advantage}

Chance originally means the landing way of a thing in ancient French and is comprehended as opportunity in a broad sense, namely, good chance and favored condition, or good circumstances. It is the harmony of individual endeavor and the social condition, and a common phenomenon in society. In fact, chance is a summation of conditions and phenomenon of the development of temporary or long standing objective things. Hence it is widely used for folk, for a nation or for mankind, and also for an individual, for a family and for an enterprise. Different people have different opinions of 'chance' and because of different cognitive abilities and their own characteristics. Most people believe that chance is luck, and cover this word with mysterious color. There seems an invisible power that controls people's fate, and the result depends on the luck entirely, which makes the success of life to the good chance which is god-given. We accept that there is some inherent link between the chance and success, but one will submit to the fate if he considers blindly that the chance is unpredictable and purely imaginary.

Some others consider that chance is taken by accident; in fact, it is the show of someone's ability of investigation, controlling a situation and evaluation. Chance can make business go smoothly and make a breakthrough, and consequently lead to the success of one's undertaking.

Some enterprises could find chance, grasp chance, utilize chance and create chance, and then make a great progress. Such a chance that benefits the development of an 
enterprise is named the situation advantage. The situation advantage is a common phenomenon in the development of an enterprise. Grasping, utilizing and creating chance have been popularly studied in the field of enterprises and management. In the face of the complicated and varied competition among enterprises, it is a trial for an enterprise to grasp and create the situation advantages, and a trial for the individual ability of an entrepreneur and the synthesis ability of an enterprise, at the same time, and meanwhile, it is the key to the subsistence and development of the enterprise. Now, the formal definition of the situation advantage will be given as follows:

Definition 1. Decision-maker $D_{i}, i \in N=\{1.2 \ldots m\}$ has different values in $\mathrm{m}$ conflict variables $x_{1}, x_{2}, \cdots, x_{m}$ and $\mathrm{S}$ is the feasible set of the conflict variable $\mathrm{X}=$ $\left(x_{1}, x_{2}, \cdots, x_{m}\right)$, then the $\mathrm{CS}=\left(\mathrm{D}_{\mathrm{i}}, \mathrm{X} \in \mathrm{S}\right)$ is defined as conflict situation.

In the competition of the same industry, the decision-maker $D_{i}$ is the actor who can really participate in the conflict and has the power to influence the eventual result. So decision-makers are limited in number. Conflict vector $\mathrm{X}$ is the tactic vector which the decision-maker can choose in $x_{i}(i \in N)$, and not every decision-maker will choose all the conflict variables, but only the variable that influences the utility of the decision-maker is the conflict variable. This variable is restricted by the power of the decision-maker, while $S$ is the scope of the enterprise game.

Definition 2. Suppose $D_{i}$ and $D_{j}$ are decision-makers, $i, j \in N, X^{i}$ and $X^{j}$ is the conflict vector of $D_{i}$ and $D_{j}$, and the utility function of $D_{i}$ and $D_{j}$ are $U_{i}\left(X^{i}\right), U_{j}\left(X^{j}\right)$ separately. The tactic choices of conflict of these two decision-makers in different conflict situations, have the same effect in conflict situations if and only if $U_{i}\left(X^{j}\right)=U_{j}\left(X^{j}\right)$.

Definition 3. Assuming $D_{i}$ is the actor in the enterprise game, $F\left(U_{1}\left(X^{1}\right), U_{2}\left(X^{2}\right.\right.$ )...... $\left.U_{m}\left(X^{m}\right)\right)$ be his ally value function. The actor $D_{i}$ would prefer strategy $X^{1}$ to strategy $\mathrm{X}^{2}$ in $\mathrm{F}$ if $\mathrm{X}^{1}=\left(\mathrm{x}_{1}{ }^{1} \mathrm{x}_{2}{ }^{1} \ldots \mathrm{x}_{\mathrm{m}}{ }^{1}\right), \mathrm{X}^{2}=\left(\mathrm{x}_{1}{ }^{2} \mathrm{x}_{2}{ }^{2} \ldots \mathrm{X}_{\mathrm{m}}{ }^{2}\right)$, satisfy $\mathrm{F}\left(\mathrm{U}_{1}\left(\mathrm{X}^{1}\right), \mathrm{U}_{2}\left(\mathrm{X}^{2}\right), \ldots \mathrm{U}_{\mathrm{m}}\left(\mathrm{X}^{\mathrm{m}}\right)\right.$ )$\sum F\left(U_{1}\left(X^{1}\right) \ldots U_{m}\left(X^{m}\right)\right.$ ), we define that the conflict situation, $C S_{1}$ is preferred to $C_{2}$ in value function $F$.

Definition 4.F $\left(\mathrm{U}_{1}\left(\mathrm{X}^{1}\right), \mathrm{U}_{2}\left(\mathrm{X}^{2}\right) \ldots . . \mathrm{U}_{\mathrm{m}}\left(\mathrm{X}^{\mathrm{m}}\right)\right)$ is ally value function, let the value of the decision-maker, $D_{i} i \in N=\{1.2 \ldots m\}$, be $X^{i}=\left(x_{1}^{i} x_{2, \ldots}^{i} x_{m}^{i}\right), S$ be the feasible set of the conflict variable. We define that $D_{i}$ has the situation advantage relative to $D_{k}, k \in N$, if the conflict situation, $C S^{\mathrm{i}}$ is preferred to $\mathrm{CS}^{\mathrm{j}}$ in ally value function $\mathrm{F}$ for any tactic choice $\mathrm{X}^{\mathrm{j}}$, $\mathrm{X}^{\mathrm{j}} \in \mathrm{S}$, in any $\mathrm{D}_{\mathrm{j}}, \mathrm{j} \in \mathrm{N}$.

\section{The Characters of Situation Advantage}

a. Transitivity: If $\mathrm{CS}_{1}$ is superior to $\mathrm{CS}_{2}$ on $\mathrm{F}, \mathrm{CS}_{2}$ to $\mathrm{CS}_{3}$ on $\mathrm{F}$, and then $\mathrm{CS}_{1}$ is superior to $\mathrm{CS}_{3}$ on $\mathrm{F}$.

b. Relativity: The situation advantage is relative to other business enterprises which take participate in the industry competition, As a result the relativity is obvious.

c. Chanciness: The emergence of situation advantage does not have the fixed regulation, which usually does not follow the normal regulation. So the situation advantage has more chancinesses. 
d. Transitoriness: The situation advantage always appears in a particular period and disappears when the time goes.

e. Development: The situation advantage is a process of formation and development. With the changes of the interior and exterior market condition and the rival's strategy, the advantage will change. Today's advantage may be changed into a disadvantage in the future. And the current disadvantage also may be changed into the future advantage.

f. Combination of subjective and objective: Situation advantage exists in every business enterprise, which the entrepreneurs need create and discover by themselves. Only the excellent boss has the talent to identify and discover the situation advantage which arises in the game process.

g. Practicality and potentiality: Not all the situation advantages of enterprises can be changed into the profits. If the situation advantage of a business enterprise is in the competition environment of a beneficial market, at the same time it can also capture the preference of customers, then the situation advantage will change into the real profits. Otherwise, it can produce little profit or nothing or produce profit only when the preference of customers is changed.

The situation advantage emphasizes that making and utilizing a transform can create the competitive advantages. On the one hand, with the fast development of science and technology and a variety of the customers' demands, the environment of enterprise is getting more and more unstable. It is not sufficient only to enhance the foresight in the dynamic situation. On the other hand, the process in which the enterprise adapts to the environment contains the content of competition with rivals. Because the conditions and targets are different, the countermeasures of different enterprises to the dynamic situation are different, too. It is impossible for a business enterprise to know its rival well. The game theory emphasizes on the rules of taking action by the feasible choices and the ability of adjusting and selecting the combinations of these rules and the formation of the ability of the new rules. The determinant factors of the situation advantage are made up of competitive information about the rivals, excellent entrepreneur and self value of the enterprise.

\section{The Determinant Factors of the Situation Advantage Formation}

\subsection{Competitive Information}

In the information society, each business enterprise who wants to survive and develop in the market competition must make an effort to obtain the political, economic and technical information related to the competition among business enterprises, especially, the competitive information related to the success or failure of the decision-making of the enterprise .It is not only the basis on which the enterprise can make out the competition strategy ,but also a basic prior condition to create a situation advantage. 
With the fast development of information technology, the competitive information has brought to more attention and has become the key factor with which the enterprise's competitive ability can be measured. In the information age, collecting and disposing information is the start point and a prerequisite in a decision-making activity. Each rival constantly changes its competition strategy. The enterprise that can control and make a good use of the competition information without delay will become stronger in the competition, and may create a kind of competition advantage: situation advantage which can benefit the enterprise's survival.

\subsection{The Characteristics of an Entrepreneur}

a. Political character. An entrepreneur can not only closely follow the market, but also the government in management. Only closely following the market is just like walking on one leg, therefore, closely following the market as well as the government is just like walking on two legs.

b. Ability character. A successful entrepreneur must have the profound knowledge, the sharp-witted observational ability, the resolute decision ability, the organizational capability and the ability of creativity.

c. Consciousness character. An entrepreneur must not only grasp the present but also seize the future in the furious competition of the market economy. He insists on setting up the superior consciousness, information consciousness and competition consciousness, and then the enterprise will remain invincible for ever.

\section{Conclusions}

In his paper, the situation advantage is defined from the angle of management innovation, which is another one of the competitive advantage of companies on the basis of the analysis of enterprise competitive advantage in the international trade. The essential characteristics of the situation advantage is discussed in detail, too, and three factors are put forward: the excellent boss, competitive information and added value,

\section{Acknowledgements}

The authors would like to thank Professor Lida Xu for his insightful and helpful comments. We are grateful for the funding from Bureau of Science and Technology in Shaanxi Province (Grant No. 2004KR59), and "985" two term "07" base in Xian Jiaotong University. 


\section{References}

1. S. Hymer, The International Operations of Nation Firms: A Study of Direct Investment (The MIT Press, Cambridge), Unpublished Ph.D. Dissertation, 1976, pp. 87.

2. M. Casson, The Entrepreneur: An Economic Theory (Macmillan Press, London, 1982).

3. J. Danning, International Production and the Multinational Enterprise (Allen \& Unwin Press, London, 1981).

4. W. Fu, The Characters Of Enterprise Boss, Corporation Administration 3, 12-13, (1999). 